\title{
Laparoscopic Total Gastrectomy for Gastric Cancer
}

\author{
Do Hyun Jung, M.D. ${ }^{1}$, Hyung-Ho Kim, M.D., Ph.D. ${ }^{1,2}$ \\ Department of Surgery, 'Seoul National University Bundang Hospital, Seongnam, '2Seoul National University College of Medicine, Seoul, Korea
}

\begin{abstract}
Laparoscopic total gastrectomy (LTG) has been more widely performed in the last decade because of improvements in the techniques and safety of laparoscopic distal gastrectomy. However, due to its technical difficulty, there are still concerns regarding the safety of LTG. Meta-analyses have shown that LTG is technically feasible, safe, and may offer advantages over open total gastrectomy for treatment of gastric cancer. Various methods of performing esophagojejunostomy have been developed in an effort to decrease the rate of anastomosis-related complications, and have ultimately improved the safety and acceptance of LTG. However, there is still a lack of level-one evidence in support of LTG. Conduct of large-scale, randomized clinical trials will be needed in order to verify the safety and efficacy of LTG. Therefore, we reviewed the current status and some of the controversies surrounding LTG.
\end{abstract}

Keywords: Laparoscopy, Gastrectomy, Stomach neoplasms
Received April 20, 2015

Accepted June 1, 2015

Corresponding author

Hyung-Ho Kim

Department of Surgery, Seoul

National University Bundang

Hospital, 300 Gumi-dong,

Bundang-gu, Seongnam 463-707,

Korea

Tel: +82-31-787-7095

Fax: +82-31-787-4055

E-mail: hhkim@snubh.org

This is an Open Access article distributed under the terms of the Creative Commons Attribution Non-Commercial License (http:// creativecommons.org/licenses/by-nc/4.0/) which permits unrestricted non-commercial use, distribution, and reproduction in any medium, provided the original work is properly cited.

Copyright @ 2015 The Journal of Minimally Invasive Surgery. All rights reserved.

\section{INTRODUCTION}

Laparoscopic distal gastrectomy (LDG) for gastric cancer has been widely accepted in clinical practice since it was first performed by Kitano in 1994. ${ }^{1}$ Since that first report, several large-scale cohort studies and meta-analyses have demonstrated the technical feasibility, surgical benefits, and safety of LDG. ${ }^{2-5}$ Large-scale randomized clinical trials (RCTs) comparing the long-term oncological outcomes between LDG and open distal gastrectomy are now underway. ${ }^{6,7}$ These RCTs will provide more concrete evidence regarding the efficacy and safety of LDG.

Laparoscopic total gastrectomy (LTG) is not yet widely accepted as a treatment option for gastric cancer because of concerns regarding its technical difficulty and safety. In addition, there are no established standard procedures for esophagojejunostomy (E-J stomy) in LTG, even though many methods have been reported in the literature. Nevertheless, LTG is increasingly being performed because of the recent developments in technologies, especially laparoscopic instruments, and the surgeons' accumulating experience of this procedure. The number of studies evaluating the technical feasibility and safety of LTG is also increasing annually, with several meta-analysis, prospective observatory studies, and RCTs, being underway or recently published.

The purpose of this article is to review the current status of LTG, focusing on its safety, technical feasibility, and surgical usefulness. It is also important that surgeons have a broad knowledge of the controversial issues regarding the use of LTG for the treatment of gastric cancer. Therefore, we reviewed the current status and some of the controversies surrounding LTG. 


\section{COMPARISON BETWEEN LTG AND OPEN TOTAL GASTRECTOMY (OTG)}

Many published articles have compared LTG with OTG in order to validate the feasibility and safety of LTG. Haverkamp et $\mathrm{al}^{8}{ }^{8}$ conducted a meta-analysis comparing LTG with OTG, and concluded that LTG had better short-term outcomes; reduced blood loss, shorter hospital stay, and reduced postoperative complications. However, only eight studies were included in this meta-analysis, and most of the included studies involved relatively small sample sizes and did not evaluate the long-term outcomes.

Since the report by Haverkamp et al, several updated metaanalyses have been published (Table 1) and showed that LTG was associated with several benefits, including reduced blood loss, less postoperative pain, quicker recovery of bowel function, earlier oral intake, shorter hospital stay, and reduced postoperative morbidity. ${ }^{9-13}$ LTG and OTG were similar in terms of the number of harvested lymph nodes (LNs), resection margin, hospital mortality, and long-term outcomes. The only disadvantage of LTG was a longer operative time. The authors concluded that LTG is technically feasible, safe, and may offer some advantages over OTG in the treatment of gastric cancer.

Unfortunately, most of the studies included in these metaanalyses had small sample sizes. Therefore, further largescale cohort studies analyzing long-term survival or RCTs are required to validate the feasibility, safety, and long-term oncological outcomes of LTG. The Korean Laparoscopic Gastrointestinal Surgery Study (KLASS)-03 trial (NCT01584336) is an ongoing phase II prospective observatory study to compare LTG and OTG in patients with clinical stage I gastric cancer with a planned sample size of 168 patients.

\section{RECONSTRUCTION METHODS}

Meta-analyses have shown that the rates of anastomosisrelated complications were not significantly different between LTG and OTG. ${ }^{8-13}$ However, there are many reconstruction methods of E-J stomy for LTG. Generally, the E-J stomy methods can be divided into two main types depending on whether a circular stapling, ${ }^{14-21}$ or linear stapling ${ }^{22-29}$ approach was used. Four circular stapling approaches have been used: extracorporeal, OrVil ${ }^{\circledR}$, endo-purse-string instrument (Endo-PSI II, Lap-Jack), and laparoscopic sutures (including Endostitch). Two linear stapling approaches have been used: overlapping and functional end-to-end stapling. Modified methods are included in the subtype to which they originally belonged.

The surgical outcomes of E-J stomy studies that enrolled

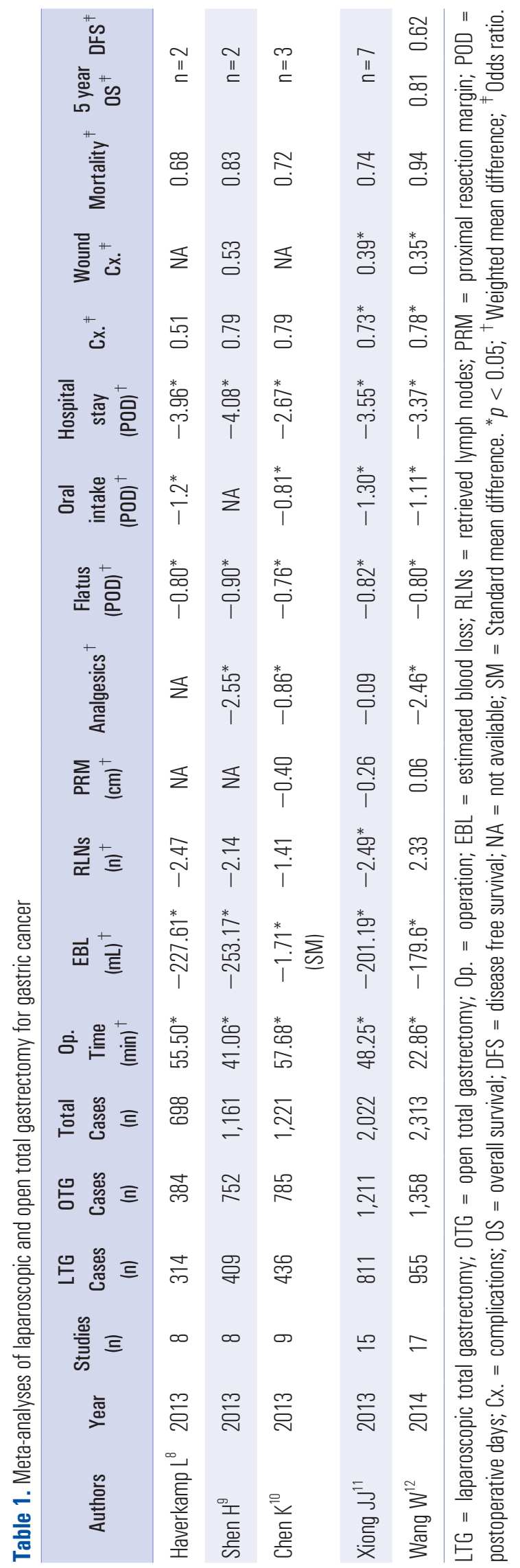




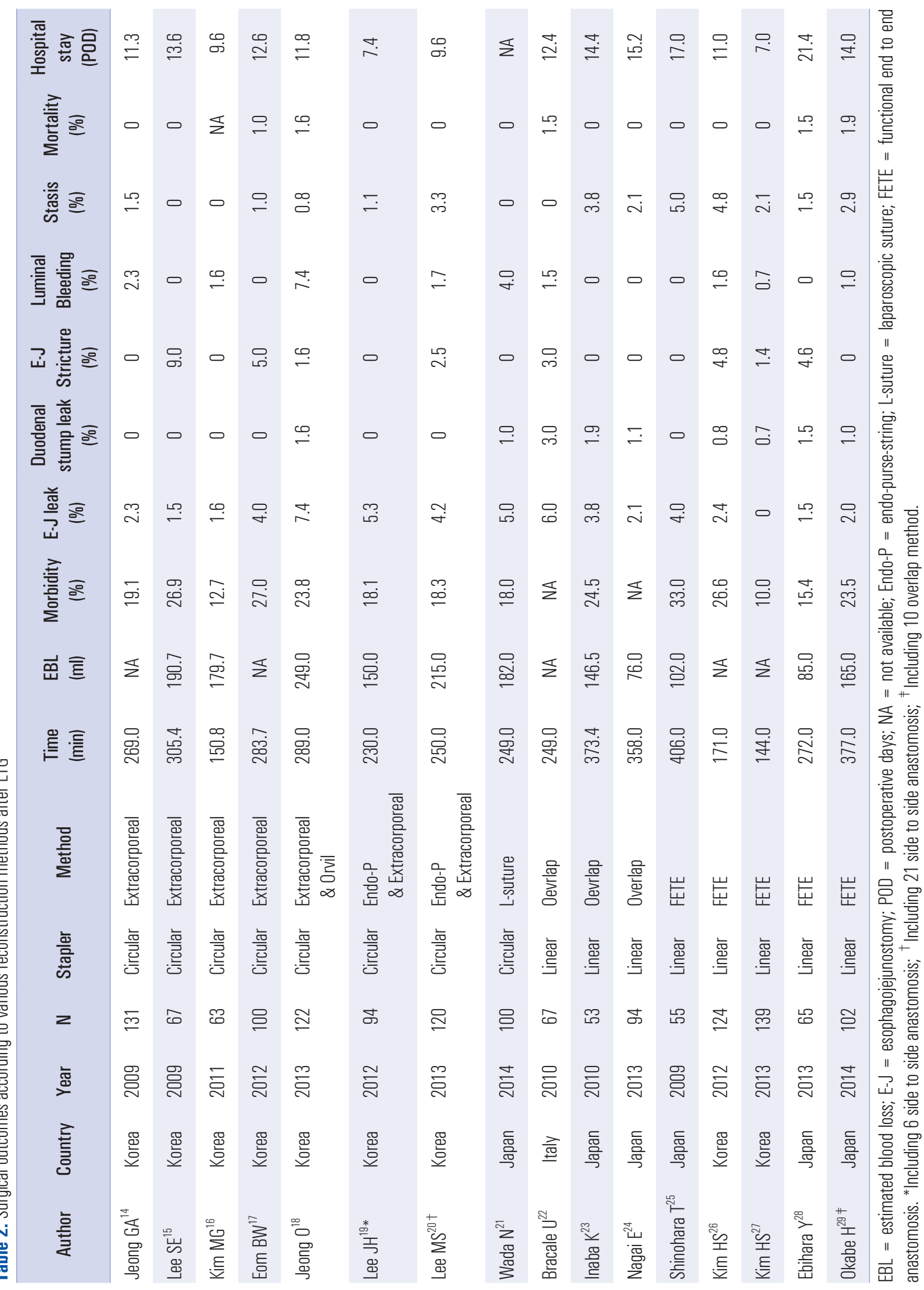


more than 50 patients are summarized in Table 2..$^{14-29}$ The surgical outcomes included operative time, estimated blood loss (EBL), overall morbidity, E-J leakage, duodenal stump leakage, E-J stricture, intraluminal bleeding, stasis (including ileus), mortality, and hospital stay.

Extracorporeal E-J stomy was performed by direct vision through a mini-laparotomy in the epigastrium. ${ }^{14-17}$ The surgical outcomes of extracorporeal E-J stomy were not significantly different from those of the other E-J stomy subgroups. However, several authors have reported some technical difficulties of this technique. For example, the purse-string clamp and straight needles were too large to be manipulated easily in a deep narrow space and the esophagus could not be adequately extracted. ${ }^{16,18}$ Two phase II prospective studies are ongoing in Korea (a secondary endpoint of KLASS-03) and China (NCT02085031) in order to compare the surgical outcomes between extracorporeal E-J stomy and intracorporeal E-J stomy. This is the secondary endpoint of the KLASS-03 trial and is also being evaluated by Guoxin $\mathrm{Li}$ et al in a Chinese RCT (planned sample size=136; NCT02085031).

Because of the technical difficulty of extracorporeal E-J stomy, many types of intracorporeal E-J stomy have been tested. ${ }^{19-29}$ However, there were no differences in the surgical outcomes between extracorporeal and intracorporeal E-J stomy or between circular and linear stapling. The rate of E-J leakage ranged from $0 \%$ to $7.4 \%$ overall, from $1.5 \%$ to $7.4 \%$ for circular stapling, ${ }^{14-21}$ and from $0 \%$ to $6 \%$ for linear stapling. ${ }^{22-29}$ The rate of E-J stricture ranged from $0 \%$ to $9 \%$ overall, from $0 \%$ to $9.0 \%$ for circular stapling, and from $0 \%$ to $4.8 \%$ for linear stapling. The rate of stasis ranged from $0 \%$ to $3.8 \%$ overall, from $0 \%$ to $3.3 \%$ for circular stapling, and from $0 \%$ to $3.8 \%$ for linear stapling.

All E-J stomy methods for LTG showed excellent surgical outcomes with low rates of anastomosis-related complications. However, no meta-analysis has compared the surgical outcomes among the different reconstruction methods used in LTG. The results of the phase II RCTs have not yet been published. Therefore, further well-designed studies are required to validate the safety and feasibility of different types of E-J stomy.

\section{LTG WITHOUT SPLENECTOMY VERSUS LTG WITH SPLENECTOMY FOR ADVANCED GASTRIC CANCER (AGC)}

As surgeons gain experience of LTG, its use has expanded from early gastric cancer (EGC) to AGC. Station 10 lymphadenectomy is an important but difficult procedure for LTG in AGC. Several authors have reported the surgical outcomes of spleen-preserving splenic hilar lymphadenectomy using LTG (Table 3) ${ }^{30,31}$ They showed that the procedure was technically feasible with a mean operative time of 169 359 min, EBL of $46 \sim 187 \mathrm{ml}$, morbidity rate of $12.0 \% \sim 18.9 \%$, and a mortality rate of $0 \%$. They also reported on the safety of this procedure. The number of retrieved LNs ranged from 44.4 to 50.8 , the number of retrieved station 10 LNs ranged from 2.6 to 3.0, and the number of metastatic station 10 LNs ranged from 0 to 2.8. However, Li et al reported that the most important factors for achieving successful station 10 lymphadenectomy are a skillful laparoscopic technique, familiarity with the vascular anatomy of the splenic hilum area, and a cooperative surgical team. They recommended that routine station 10 lymphadenectomy may be unnecessary for AGC without serosal invasion, unless T3 tumors are located in the greater curvature of the stomach.

The necessity of splenectomy for station 10 lymphadenectomy was not supported by the Japanese Clinical Oncology Group (JCOG) 0110 trial, an RCT in which OTG with splenectomy was compared with OTG without splenectomy (NCT00112099). ${ }^{32}$ In particular, the morbidity rate was significantly greater for OTG with splenectomy than for OTG

Table 3. Surgical outcomes of laparoscopic total gastrectomy without splenectomy vs. with splenectomy

\begin{tabular}{|c|c|c|c|c|c|c|c|c|c|c|c|c|}
\hline Author & Country & Year & $\begin{array}{c}\text { Splenectomy } \\
(\%)\end{array}$ & N & $\begin{array}{l}\text { Op. time } \\
\text { (min) }\end{array}$ & $\begin{array}{l}\text { EBL } \\
\text { (ml) }\end{array}$ & $\begin{array}{l}\text { Hospital stay } \\
\text { (POD) }\end{array}$ & $\begin{array}{l}\text { RLNs } \\
\text { (n) }\end{array}$ & $\begin{array}{c}\text { Morbidity } \\
(\%)\end{array}$ & $\begin{array}{c}\text { Mortality } \\
(\%)\end{array}$ & $\begin{array}{l}\text { RLNs of } \\
\text { №. } 10 \text { (n) }\end{array}$ & $\begin{array}{c}\text { MLNs of } \\
\text { No. } 10(\%)\end{array}$ \\
\hline$L_{i} P^{31}$ & China & 2014 & 0 (SP) & 108 & 169 & 46 & 11.9 & 44.4 & 12.0 & 0 & 3.0 & 2.8 \\
\hline Okabe $\mathrm{H}^{30}$ & Japan & 2010 & $0(S P)$ & 53 & 359 & 187 & 13.0 & 50.8 & 18.9 & 0 & 2.6 & 0 \\
\hline Nakata $K^{33}$ & Japan & 2014 & 100 (SR) & 18 & 388 & 45 & 12.0 & 51.0 & 27.8 & 0 & NA & NA \\
\hline Shinohara $\mathrm{T}^{25}$ & Japan & 2009 & 56 & 55 & 406 & 102 & 17.0 & 46.0 & 33.0 & 0 & NA & NA \\
\hline Lee $\mathrm{JH}^{19}$ & Korea & 2012 & 51 & 94 & 230 & 150 & 7.4 & 60.5 & $18.1^{*}$ & 0 & NA & NA \\
\hline
\end{tabular}

$\mathrm{Op} .=$ operation; $\mathrm{EBL}=$ estimated blood loss; RLNs = retrieved lymph nodes; MLNs = metastatic lymph nodes; $\mathrm{POD}=$ postoperative days; $\mathrm{SP}=$ spleen preserving; $S R=$ splenectomy; NA = not available. ${ }^{*}$ Morbidity requiring medical or surgical interventions Igrade II or higher of Clavien-Dindo classification) were regarded as an event. 
without splenectomy (30.3\% vs. $16.7 \%$, respectively). ${ }^{32}$ In a study of LTG with splenectomy, Nakata et al. ${ }^{33}$ reported that the morbidity rate was $27.8 \%$, which was greater than that of LTG without splenectomy, for which the morbidity rate ranged from $12 \%$ to $18.9 \% .^{30,31}$ The study by Shinohara et al., ${ }^{25}$ which included a large proportion of patients who underwent splenectomy, reported a high rate of complications (33\%). However, Lee et al. ${ }^{19}$ reported that the rate of complications in their study $(18.1 \%)$ was similar to the rate reported in other studies of LTG without splenectomy $\left(12 \%\right.$ 18.9\%). ${ }^{30,31}$ The experience of the surgeon, the level of cooperation of the surgical team, and advances in laparoscopic instruments help to reduce the morbidity rate of LTG with splenectomy. Because LTG was associated with lower morbidity than OTG in two updated meta-analyses, ${ }^{11,12}$ the JCOG 0110 OTG trials do not allow conclusions to be made on the safety LTG. More studies comparing LTG with and without splenectomy are therefore necessary.

\section{LAPAROSCOPIC-COMPLETED TOTAL GASTRECTOMY FOR REMNANT GASTRIC CANCER}

As the indication for LTG has expanded from EGC to AGC, reflecting the advances made in laparoscopic instruments and techniques, more and more completion total gastrectomies have been performed laparoscopically. Three studies have compared laparoscopic completion total gastrectomy and open completion total gastrectomy (Table 4). ${ }^{34-36}$ Laparoscopic completion total gastrectomy had similar surgical outcomes to open completion total gastrectomy, except the former had a significantly longer operative time. Laparoscopic completion total gastrectomy was technically feasible and reliable, but offered no definitive clinical advantage over open completion total gastrectomy. ${ }^{36}$

\section{LEARNING CURVE OF LTG}

Jeong et al. reported that the postoperative morbidity rate reached a plateau after around 45 patients. ${ }^{37}$ By contrast, Jung et al reported that the first generation of surgeons needed to conduct approximately 100 LTG cases to overcome the learning curve..$^{38}$ The first generation of surgeons who performed the technique did not have a standardized procedure or an established training system. Several other studies showed that about 50 60 LDG cases were required to overcome the learning curve in the first generation of surgeons. ${ }^{39,40}$ However, several recent studies have reported that the learning curve for LDG could be decreased by standardizing the surgical technique and by establishing a training system. ${ }^{41,42}$ Therefore, it is predicted that the LTG learning curve will be much shorter for the second generation of surgeons.

\section{DUAL-PORT OR SINGLE-PORT LTG}

Kunisaki et $a .^{43}$ and Kawamura et al. ${ }^{44}$ compared conventional LTG with dual-port LTG (Table 5). Kunisaki et al. reported that the operative time was significantly longer with dual-port LTG (319.0 min) than with conventional LTG (259.0 $\mathrm{min})$. However, the EBL, the number of retrieved LNs, and the morbidity rate were similar in both groups. Meanwhile, Kawamura et al reported that all surgical outcomes, including operative time, were similar between the two groups. Both research groups concluded that dual-port LTG is acceptable for the treatment of gastric cancer requiring total gastrectomy, when performed by surgeons sufficiently experienced in conventional LTG.

Table 4. Comparative studies of laparoscopic and open completion total gastrectomy

\begin{tabular}{|c|c|c|c|c|c|c|c|c|c|c|c|c|}
\hline Author & Country & Year & Approach & N & $\begin{array}{l}\text { Op. } \\
\text { time } \\
\text { (min) }\end{array}$ & $\begin{array}{l}\text { EBL } \\
(\mathrm{mL})\end{array}$ & $\begin{array}{l}\text { Hospital } \\
\text { stay } \\
\text { (POD) }\end{array}$ & $\begin{array}{l}\text { RLNs } \\
\text { (n) }\end{array}$ & $\begin{array}{c}\text { Morbidity } \\
(\%)\end{array}$ & $\begin{array}{c}\text { Mortality } \\
(\%)\end{array}$ & $\begin{array}{l}5 \text { year } \\
\text { OS (\%) }\end{array}$ & $\begin{array}{c}\text { Open } \\
\text { conversion } \\
(\%)\end{array}$ \\
\hline \multirow[t]{2}{*}{ Nagai ${ }^{34}$} & Japan & 2014 & Laparoscopy & 12 & $362.3^{*}$ & $65.8^{*}$ & $11.3^{*}$ & 23.7 & 0 & 0 & 77.8 & 0 \\
\hline & & & Open & 10 & $270.5^{*}$ & $746.3^{*}$ & $24.9^{*}$ & 15.9 & 20.0 & 0 & 72.9 & NA \\
\hline \multirow[t]{2}{*}{ Kwon IG ${ }^{35}$} & Korea & 2014 & Laparoscopy & 18 & $266.2^{*}$ & 182.0 & $6.0^{*}$ & 8.0 & 33.3 & 0 & 100 & 5.6 \\
\hline & & & Open & 58 & $203.3^{*}$ & 193.0 & $9.0^{*}$ & 7.0 & 44.8 & 0 & 94.9 & NA \\
\hline \multirow[t]{2}{*}{ Son $S Y^{36}$} & Korea & 2015 & Laparoscopy & 17 & $234.4^{*}$ & 228.0 & 9.3 & 18.8 & 35.2 & 0 & 66.7 & 47.1 \\
\hline & & & Open & 17 & $170.0^{*}$ & 184.0 & 9.3 & 22.3 & 29.4 & 0 & 60.3 & NA \\
\hline
\end{tabular}

Op. = operation; $\mathrm{EBL}=$ estimated blood loss; $\mathrm{POD}=$ postoperative days; $\mathrm{RLNs}=$ retrieved lymph nodes; $\mathrm{OS}=$ overall survival; $\mathrm{NA}=$ not applicable. ${ }^{*} p<0.05$. 
Table 5. Surgical outcomes of dual port and single port laparoscopic total gastrectomy

\begin{tabular}{lccccccccccc}
\multicolumn{1}{c}{ Author } & Country & Year & $\mathbf{N}$ & $\begin{array}{c}\text { Port } \\
(\mathbf{n})\end{array}$ & $\begin{array}{c}\text { BMI } \\
\left(\mathbf{k g} / \mathbf{m}^{2}\right)\end{array}$ & $\begin{array}{c}\text { Op. time } \\
(\mathbf{m i n})\end{array}$ & $\begin{array}{c}\text { EBL } \\
(\mathbf{m l})\end{array}$ & $\begin{array}{c}\text { Hospital } \\
\text { stay (POD) }\end{array}$ & $\begin{array}{c}\text { RLNs } \\
(\mathbf{n})\end{array}$ & $\begin{array}{c}\text { Morbidity } \\
(\%)\end{array}$ & $\begin{array}{c}\text { Mortality } \\
(\%)\end{array}$ \\
\hline Kawamura $\mathrm{H}^{44}$ & Japan & 2013 & 10 & 2 & 23.8 & 253.0 & 33.4 & 11 & 31.6 & 0 & 0 \\
& & & 10 & 5 & 23.6 & 235.5 & 39.8 & NA & 40.9 & 10.0 & 0 \\
Kunisaki C & Japan & 2014 & 45 & 2 & 22.7 & $319.0^{*}$ & 93.7 & $16.3^{*}$ & 46.3 & 13.3 & 0 \\
& & & 45 & 5 & 22.3 & $259.0^{*}$ & 118.9 & $27.0^{*}$ & 46.6 & 28.9 & 0 \\
Ertem M M $^{46}$ & Turkey & 2013 & 1 & 1 & 22.1 & 282.0 & NA & 8 & 34.0 & 0 & 0 \\
Ahn SH $^{45}$ & Korea & 2014 & 2 & 1 & 18.95 & 190.0 & 55.0 & 6 & 76.5 & 0 & 0 \\
\hline
\end{tabular}

Op. $=$ operation; EBL $=$ estimated blood loss; $\mathrm{POD}=$ postoperative days; RLNs $=$ retrieved lymph nodes; $\mathrm{NA}=$ not available. ${ }^{*} p<0.05$.

Ahn et al. ${ }^{45}$ and Ertem et al. ${ }^{46}$ reported several patients who successfully underwent single-port LTG (Table 5). The surgical outcomes of single-port LTG were not significantly different from those of dual-port LTG or conventional LTG. However, these reports cannot confirm the technical feasibility of single-port LTD because only one or two cases were included in each report.

Although several studies have been reported to date, the feasibility and safety of dual-port or single-port LTG have not yet been confirmed. Nevertheless, the results to date suggest that LTG will develop into a less-invasive procedure, reflecting the advances in laparoscopic instruments and techniques, and the increasing number of experienced surgeons and excellent surgical teams.

\section{CONCLUSION}

Multiple meta-analyses have shown that LTG is technically feasible, safe, and may offer some advantages over OTG for the treatment of gastric cancer. All E-J stomy methods for LTG had excellent surgical outcomes with low rates of anastomosisrelated complications. The optimal E-J stomy method should be selected based on the individual patient's characteristics (for example, body mass index), tumor characteristics (for example gastroesophageal junctional invasion), and the surgeon's technical abilities. However, there is still no level-one evidence supporting the technical feasibility, surgical usefulness, or safety of LTG. Therefore, large-scale RCTs and meta-analyses of these large-scale RCTs are still necessary.

There has been much debate about whether LTG with or without splenectomy is superior for AGC. It is also debated whether laparoscopic-completed total gastrectomy is better than open-completed total gastrectomy for remnant gastric cancer and whether conventional LTG, or dual-port or singleport LTG is preferable. Advances in laparoscopic instruments, the introduction of high-resolution laparoscopes, continual improvements in techniques, and further studies will help address these questions. Overall, we believe that these refinements will further improve the safety and reduce the invasiveness of LTG.

\section{REFERENCES}

1) Kitano $S$, Iso $Y$, Moriyama M, Sugimachi K. Laparoscopy-assisted Billroth I gastrectomy. Surg Laparosc Endosc 1994;4:146-148.

2) Zeng YK, Yang ZL, Peng JS, Lin HS, Cai L. Laparoscopy-assisted versus open distal gastrectomy for early gastric cancer: evidence from randomized and nonrandomized clinical trials. Ann Surg 2012;256:39-52.

3) Vinuela EF, Gonen M, Brennan MF, Coit DG, Strong VE. Laparoscopic versus open distal gastrectomy for gastric cancer: a meta-analysis of randomized controlled trials and high-quality nonrandomized studies. Ann Surg 2012;255:446-456.

4) Jiang L, Yang KH, Guan QL, et al. Laparoscopy-assisted gastrectomy versus open gastrectomy for resectable gastric cancer: an update meta-analysis based on randomized controlled trials. Surg Endosc 2013;27:2466-2480.

5) Kim HH, Han SU, Kim MC, et al. Long-term results of laparoscopic gastrectomy for gastric cancer: a large-scale case-control and case-matched Korean multicenter study. J Clin Oncol 2014; 32:627-633.

6) Kim HH, Han SU, Kim MC, et al. Prospective randomized controlled trial (phase III) to comparing laparoscopic distal gastrectomy with open distal gastrectomy for gastric adenocarcinoma (KLASS 01). J Korean Surg Soc 2013;84:123-130.

7) Nakamura K, Katai H, Mizusawa J, et al. A phase III study of laparoscopy-assisted versus open distal gastrectomy with nodal dissection for clinical stage IA/IB gastric Cancer (JCOG0912). Jpn J Clin Oncol 2013;43:324-327.

8) Haverkamp L, Weijs TJ, van der Sluis PC, van der Tweel I, Ruurda JP, van Hillegersberg R. Laparoscopic total gastrectomy versus open total gastrectomy for cancer: a systematic review and 
meta-analysis. Surg Endosc 2013;27:1509-1520.

9) Shen H, Shan C, Liu S, Qiu M. Laparoscopy-assisted versus open total gastrectomy for gastric cancer: a meta-analysis. J Laparoendosc Adv Surg Tech A 2013;23:832-840.

10) Chen K, Xu XW, Zhang RC, Pan Y, Wu D, Mou YP. Systematic review and meta-analysis of laparoscopy-assisted and open total gastrectomy for gastric cancer. World J Gastroenterol 2013;19:5365-5376.

11) Xiong JJ, Nunes QM, Huang $W$, et al. Laparoscopic vs open total gastrectomy for gastric cancer: a meta-analysis. World J Gastroenterol 2013;19:8114-8132.

12) Wang $W$, Zhang $X$, Shen $C$, Zhi X, Wang B, Xu Z. Laparoscopic versus open total gastrectomy for gastric cancer: an updated metaanalysis. PLoS One 2014;9:e88753.

13) Wang W, Li Z, Tang J, Wang M, Wang B, Xu Z. Laparoscopic versus open total gastrectomy with D2 dissection for gastric cancer: a meta-analysis. J Cancer Res Clin Oncol 2013;139:17211734.

14) Jeong GA, Cho GS, Kim HH, Lee HJ, Ryu SW, Song KY. Laparoscopy-assisted total gastrectomy for gastric cancer: a multicenter retrospective analysis. Surgery 2009;146:469-474.

15) Lee SE, Ryu KW, Nam BH, et al. Technical feasibility and safety of laparoscopy-assisted total gastrectomy in gastric cancer: a comparative study with laparoscopy-assisted distal gastrectomy. J Surg Oncol 2009;100:392-395.

16) Kim MG, Kim BS, Kim TH, Kim KC, Yook JH, Kim BS. The effects of laparoscopic assisted total gastrectomy on surgical outcomes in the treatment of gastric cancer. J Korean Surg Soc 2011;80:245-250.

17) Eom BW, Kim YW, Lee SE, et al. Survival and surgical outcomes after laparoscopy-assisted total gastrectomy for gastric cancer: case-control study. Surg Endosc 2012;26:3273-3281.

18) Jeong O, Jung MR, Kim GY, Kim HS, Ryu SY, Park YK. Comparison of short-term surgical outcomes between laparoscopic and open total gastrectomy for gastric carcinoma: case-control study using propensity score matching method. J Am Coll Surg 2013;216:184-191.

19) Lee JH, Ahn SH, Park do J, Kim HH, Lee HJ, Yang HK. Laparoscopic total gastrectomy with D2 lymphadenectomy for advanced gastric cancer. World J Surg 2012;36:2394-2399.

20) Lee MS, Lee JH, Park do J, Lee HJ, Kim HH, Yang HK. Comparison of short- and long-term outcomes of laparoscopicassisted total gastrectomy and open total gastrectomy in gastric cancer patients. Surg Endosc 2013;27:2598-2605.

21) Wada N, Kurokawa Y, Takiguchi S, et al. Feasibility of laparoscopy-assisted total gastrectomy in patients with clinical stage I gastric cancer. Gastric Cancer 2014;17:137-140.

22) Bracale U, Marzano E, Nastro P, et al. Side-to-side esophagojejunostomy during totally laparoscopic total gastrectomy for malignant disease: a multicenter study. Surg Endosc 2010;24:2475-
2479.

23) Inaba $\mathrm{K}$, Satoh $\mathrm{S}$, Ishida $\mathrm{Y}$, et al. Overlap method: novel intracorporeal esophagojejunostomy after laparoscopic total gastrectomy. J Am Coll Surg 2010;211:e25-29.

24) Nagai E, Ohuchida K, Nakata K, et al. Feasibility and safety of intracorporeal esophagojejunostomy after laparoscopic total gastrectomy: inverted T-shaped anastomosis using linear staplers. Surgery 2013;153:732-738.

25) Shinohara T, Kanaya S, Taniguchi K, Fujita T, Yanaga K, Uyama I. Laparoscopic total gastrectomy with D2 lymph node dissection for gastric cancer. Arch Surg 2009;144:1138-1142.

26) Kim HS, Kim MG, Kim BS, Yook JH, Kim BS. Totally laparoscopic total gastrectomy using endoscopic linear stapler: early experiences at one institute. J Laparoendosc Adv Surg Tech A 2012;22:889-897.

27) Kim HS, Kim BS, Lee IS, Lee S, Yook JH, Kim BS. Comparison of totally laparoscopic total gastrectomy and open total gastrectomy for gastric cancer. J Laparoendosc Adv Surg Tech A 2013; 23:323-331.

28) Ebihara Y, Okushiba S, Kawarada Y, Kitashiro S, Katoh H. Outcome of functional end-to-end esophagojejunostomy in totally laparoscopic total gastrectomy. Langenbecks Arch Surg 2013;398: 475-479.

29) Okabe H, Obama K, Tsunoda S, Tanaka E, Sakai Y. Advantage of completely laparoscopic gastrectomy with linear stapled reconstruction: a long-term follow-up study. Ann Surg 2014;259:109116.

30) Okabe H, Obama K, Kan T, Tanaka E, Itami A, Sakai Y. Medial approach for laparoscopic total gastrectomy with splenic lymph node dissection. J Am Coll Surg 2010;211:e1-6.

31) Li P, Huang CM, Zheng CH, et al. Laparoscopic spleen-preserving splenic hilar lymphadenectomy in 108 consecutive patients with upper gastric cancer. World J Gastroenterol 2014;20:11376-11383.

32) Sano T, Yamamoto S, Sasako M. Randomized controlled trial to evaluate splenectomy in total gastrectomy for proximal gastric carcinoma: Japan clinical oncology group study JCOG 0110-MF. Jpn J Clin Oncol 2002;32:363-364.

33) Nakata K, Nagai E, Ohuchida K, Shimizu S, Tanaka M. Technical feasibility of laparoscopic total gastrectomy with splenectomy for gastric cancer: clinical short-term and long-term outcomes. Surg Endosc 2014. (in press)

34) Nagai E, Nakata K, Ohuchida K, Miyasaka Y, Shimizu S, Tanaka M. Laparoscopic total gastrectomy for remnant gastric cancer: feasibility study. Surg Endosc 2014;28:289-296.

35) Kwon IG, Cho I, Guner A, et al. Minimally invasive surgery for remnant gastric cancer: a comparison with open surgery. Surg Endosc 2014:28:2452-2458.

36) Son SY, Lee CM, Jung DH, et al. Laparoscopic completion total gastrectomy for remnant gastric cancer: a single-institution experience. Gastric Cancer 2015;18:177-182. 
37) Jeong O, Ryu SY, Choi WY, Piao Z, Park YK. Risk factors and learning curve associated with postoperative morbidity of laparoscopic total gastrectomy for gastric carcinoma. Ann Surg Oncol 2014;21:2994-3001.

38) Jung DH, Son SY, Park YS, et al. The learning curve associated with laparoscopic total gastrectomy. Gastric Cancer 2014. (in press)

39) Zhang $X$, Tanigawa N. Learning curve of laparoscopic surgery for gastric cancer, a laparoscopic distal gastrectomy-based analysis. Surg Endosc 2009;23:1259-1264.

40) Kim MC, Jung GJ, Kim HH. Learning curve of laparoscopyassisted distal gastrectomy with systemic lymphadenectomy for early gastric cancer. World J Gastroenterol 2005;11:7508-7511.

41) Nunobe S, Hiki N, Tanimura S, Nohara K, Sano T, Yamaguchi $\mathrm{T}$. The clinical safety of performing laparoscopic gastrectomy for gastric cancer by trainees after sufficient experience in assisting. World J Surg 2013;37:424-429.

42) Tokunaga M, Hiki N, Fukunaga T, et al. Learning curve of laparo- scopy-assisted gastrectomy using a standardized surgical technique and an established educational system. Scand J Surg 2011;100:8691.

43) Kunisaki C, Makino H, Kimura J, et al. Application of reducedport laparoscopic total gastrectomy in gastric cancer preserving the pancreas and spleen. Gastric Cancer 2014. (in press)

44) Kawamura H, Tanioka T, Kuji M, Tahara M, Takahashi M. The initial experience of dual port laparoscopy-assisted total gastrectomy as a reduced port surgery for total gastrectomy. Gastric Cancer 2013;16:602-608.

45) Ahn SH, Park do J, Son SY, Lee CM, Kim HH. Single-incision laparoscopic total gastrectomy with D1+beta lymph node dissection for proximal early gastric cancer. Gastric Cancer 2014;17:392-396.

46) Ertem M, Ozveri E, Gok H, Ozben V. Single incision laparoscopic total gastrectomy and $\mathrm{d} 2$ lymph node dissection for gastric cancer using a four-access single port: the first experience. Case Rep Surg 2013;2013:504549. 